\title{
Partnership for Research \& Education in Plants (PREP): Involving High School Students in Authentic Research in Collaboration with Scientists
}

Author(s): Eric Brooks , Erin Dolan , Frans Tax

Source: The American Biology Teacher, 73(3):137-142. 2011.

Published By: National Association of Biology Teachers

URL: http://www.bioone.org/doi/full/10.1525/abt.2011.73.3.4

BioOne (www.bioone.org) is a nonprofit, online aggregation of core research in the biological, ecological, and environmental sciences. BioOne provides a sustainable online platform for over 170 journals and books published by nonprofit societies, associations, museums, institutions, and presses.

Your use of this PDF, the BioOne Web site, and all posted and associated content indicates your acceptance of BioOne's Terms of Use, available at www.bioone.org/page/terms_of_use.

Usage of BioOne content is strictly limited to personal, educational, and non-commercial use. Commercial inquiries or rights and permissions requests should be directed to the individual publisher as copyright holder. 
RESEARCH ON

LEA R N I N G

Partnership for Research

\& Education in Plants (PREP):

Involving High School Students

in Authentic Research in

Collaboration with Scientists

\section{Abstract}

A partnership between scientists, high school teachers, and their students provides authentic research experiences to help students understand the nature and processes of science. The Partnership for Research and Education in Plants (PREP) engages students in a large-scale genomics research project using classroom-tested protocols that can help to find the function of a disabled gene in the widely studied plant Arabidopsis thaliana. Here, we describe the framework of PREP in the classroom within the context of the National Science Education Standards.

Key Words: Arabidopsis; inquiry learning; authentic research; plants.

Biology teachers must make a number of challenging instructional decisions throughout the academic year, including choosing what content is most important to teach, how to engage students and keep them focused during activities, and how to help students learn about science concepts as well as the nature and processes of science. The teacher-led demonstrations, laboratory activities with predictable outcomes, and "quick labs" found in most high school textbooks all have their place in the science classroom, but most fall short of providing teachers with ideal solutions to these challenges.

University and college scientists face a separate set of challenges. With increasing competition for extramural funding and the requirement by some funding agencies to participate in K-12 outreach, scientists are often looking for creative ways to meet outreach requirements that help them stay competitive for research grants and demonstrate the societal impacts of their research. In the last decade, genomic-based projects studying various organisms have become a main driving force for research across the country. The 2010 Project, for instance, was established to develop a comprehensive understanding of the functions of genes in the model plant Arabidopsis thaliana by 2010 (National Science Foundation, 2001), in order to better understand how flowering plants grow and adapt to their environment.
The Partnership for Research and Education in Plants (PREP; Lally et al., 2007; Dolan et al., 2008) attempts to meet the needs of teachers and scientists by providing a framework for collaborative research to study gene function in Arabidopsis. PREP gives teachers a structure for their students to participate in a complete research project that has the potential to add to the body of knowledge about flowering plants. PREP allows both teachers and students to move away from "cookbook" labs and activities by conducting experiments with unknown outcomes that address the National Science Education Standards for inquiry learning (National Research Council [NRC], 1996). Additionally, PREP provides a framework for teachers to present unifying concepts and processes, which is a primary standard presented by the NRC (1996). Teachers can utilize PREP to present content topics such as systems, organization, models, and explanations, as well as measurement, form, and function. For scientists, PREP provides an opportunity to engage the public in their research.

One way to initiate PREP is for teachers to identify a university or college scientist (hereafter, "scientist") with whom to collaborate. Strategies for identifying partners are outlined in Table 1 . The next step is to establish a plan for the project, including how materials will be acquired, who will be responsible for which aspect of the project, and what the timeline or schedule will be for the experiments and interactions among the teacher, students, and scientist (see Table 2). In most cases, materials for sowing and growing plants are provided by the scientist, whereas supplies and materials needed for certain treatments are acquired by the school, teachers, or students themselves. Teachers and scientists should agree on how and when the scientist will be involved in the project. Some teachers primarily involve their scientist partner as a source of seeds and plant-growth supplies. Others host the scientist for a classroom visit, or encourage their students to correspond with the scientist via e-mail or online video chats. No matter what agreement is reached, there are three

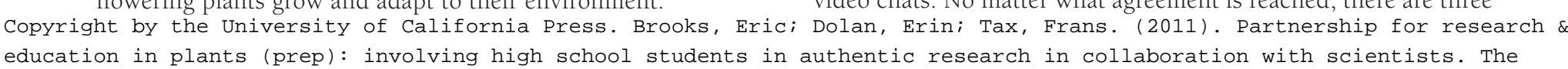
American Biology Teacher, 73(3), 137-142. doi: 10.1525/abt.2011.73.3.4

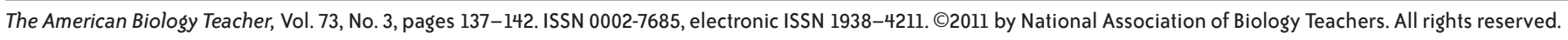

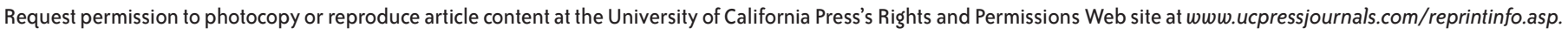
DOI: 10.1525/abt.2011.73.3.4 


\begin{tabular}{|l|l|}
\hline Looking for a scientist partner? & Looking for a teacher partner? \\
\hline $\begin{array}{l}\text { Search the website of a college or university in your area for } \\
\text { plant scientists studying Arabidopsis. }\end{array}$ & $\begin{array}{l}\text { Search the website of a high school in your area for teachers } \\
\text { teaching biology or environmental science courses. }\end{array}$ \\
\hline $\begin{array}{l}\text { Contact PREP personnel (principal investigator Erin Dolan, } \\
\text { program coordinator David Lally). }\end{array}$ & $\begin{array}{l}\text { Contact the science instruction point-of-contact (e.g., science } \\
\text { coordinator or supervisor) in the school district in your area. }\end{array}$ \\
\hline $\begin{array}{l}\text { Visit http://www.arabidopsis.org/, click on "search" and } \\
\text { "people/labs," and search for an Arabidopsis biologist in } \\
\text { your area. }\end{array}$ & $\begin{array}{l}\text { Visit the Building a Presence for Science website (http:// } \\
\text { ecommerce.nsta.orglbapl) to find the individual responsible for } \\
\text { disseminating information about science learning opportunities. }\end{array}$ \\
\hline $\begin{array}{l}\text { Once you identify a university lab, ask the professor who would } \\
\text { be the appropriate person to visit your class. Sometimes s/he } \\
\text { can recommend a talented postdoctoral fellow or graduate } \\
\text { student who has an interest in outreach in schools. }\end{array}$ & $\begin{array}{l}\text { Ask your undergraduate student about their high school } \\
\text { biology teacher. }\end{array}$ \\
\hline Talk to your children's college professors. & Talk with your children's high school teachers. \\
\hline
\end{tabular}

\section{Table 2. Points for discussion between scientists and teachers.}

\begin{tabular}{|l|l|}
\hline Topic & Discussion Points \\
\hline $\begin{array}{l}\text { Materials for students' } \\
\text { experiments }\end{array}$ & $\begin{array}{l}\text { - Standard experimental materials such as pots, trays, soil, lights, racks, fertilizer, and light timers } \\
\text { (not required) can typically be provided by the scientist } \\
\text { - Seeds in tubes, agarose, and pipettes to plant them should be provided by the scientist } \\
\text { - Specific experimental materials students need to conduct their research should be acquired by } \\
\text { the students themselves, or can be found in the high school chemistry department, although } \\
\text { scientists may be able to provide specialized materials }\end{array}$ \\
\hline Roles for the scientist & $\begin{array}{l}\text { - How often will the scientist visit the classroom (if at all)? } \\
\text { - Will discussion be in person, on the phone, or online via video chats, e-mail, or instant messaging? } \\
\text { - Will the scientist provide specific background about the seeds under study? }\end{array}$ \\
\hline
\end{tabular}

points at which students benefit from discussing their experiments with a scientist: (1) at the start, when they are first learning about Arabidopsis and the gene(s) they will be studying; (2) once their experiments are underway and they are making decisions about which data to collect and whether they are seeing meaningful differences between wild-type and mutant plants; and (3) after their analysis is complete, when the scientist can help the students consider their results in the context of what is known about the gene and Arabidopsis.

This is not a lock-step process that must be followed the same way every time. The project is flexible, and teachers can tailor it in ways that meet their students' needs and allow them to express their own creativity and personality. For example, classes with a more environmental focus can emphasize growth conditions related to climate change or the effects of pollutants. Here, we outline a general structure for the implementation of PREP in the classroom. The PREP website (http://www.prep.biotech.vt.edu) provides additional details, including guidelines for interaction (Table 3) and information about materials and methods. Teachers should feel free to modify it in anyway necessary to meet their needs and the needs of their students.

At first glance, PREP may seem daunting, but it is worth noting that teachers have successfully implemented PREP in many states. For example, in the 2009-2010 school year in Virginia, 2,237 students participated in PREP. Of those students, more than half (57\%) were in Honors Biology and 23\% were in standard biology classes.
The remaining enrollment was in AP/IB Biology or Environmental Science (8\%) and life-science electives (12\%), such as biotechnology, genetics, and horticulture. These numbers demonstrate that PREP is not limited to advanced classes, but can be integrated in a broad range of biology courses. To provide a step-by-step description of the PREP experiment for teachers and scientists, we detail its implementation in a typical classroom below.

\section{$O$ The PREP Experiment}

PREP can be broken into three phases (Figure 1). Phase 1 introduces PREP and its experimental design. Phase 2 includes growth and data collection. Phase 3 concludes the experiment with data analysis and the communication of results. The timeline (Figure 1) shows the general flow of suggested topics and activities throughout the 9-week project. Teachers are free to modify this timeline, expanding or reducing the duration of each activity or adding or removing lessons according to students' and their own needs and interests. Many of the steps in PREP have accompanying resources or videos on the PREP website (see Table 3).

\section{Phase 1A: Introducing PREP}

It is important to assess what the students already know about plants, since this knowledge will guide their thinking about how they could alter the plants' environment. This can be accomplished by planting a small houseplant in a jar, watering it, and then sealing the jar. The "plant in a jar" (NRC, 1996) provides a context for discussing plant biology 
Table 3. Important links to the PREP website.

\begin{tabular}{|l|l|}
\hline Topic & PREP website \\
\hline Model Organisms & $\begin{array}{l}\text { http://www.prep.biotech.vt.edu/timeline/ } \\
\text { Select the "germination"link and look under "lessons" }\end{array}$ \\
\hline T-DNA Insertion Animation & http://www.prep.biotech.vt.edu/timeline/files/David_Ryan_two.html \\
\hline Experimental Conditions & $\begin{array}{l}\text { http://www.prep.biotech.vt.edu/expinfo/expinfo_light.html } \\
\text { Remember that students do not have to pick from these }\end{array}$ \\
\hline Growth Conditions & http://www.prep.biotech.vt.edu/expinfo/expinfo_standard.html \\
\hline Growing Arabidopsis & http://www.prep.biotech.vt.edu/expinfo/expinfo_videos.html \\
\hline
\end{tabular}

(e.g., metabolic processes, environmental conditions needed for growth and development, relationships between phenotype and the environment) by posing the question, "How long will a plant live in a sealed jar if it starts with all the requirements necessary for good health?"

The next step is introducing PREP, which can be done by the teacher or the scientist. For example, in most classrooms, the scientist explains why plants are important to people, why Arabidopsis is important to the scientific community, and what features make an organism a good model for research (resources for this discussion are given in Table 3). The scientist explains that Arabidopsis is small and does not need much space to grow, develops rapidly and produces many offspring, and has a completely sequenced genome. In addition, Arabidopsis has an almost comprehensive set of "knock-out" mutants (i.e., there are lines of seeds with each of the approximately 25,000 genes disabled). Thousands of scientists around the world study Arabidopsis, and many of their results are freely available online (visit The Arabidopsis Information Resource at http://www.arabidopsis.org). Ideas that can be highlighted include the applications of a complete genome sequence, as well as how the mutants are generated (i.e., mutants have T-DNA, or transferred DNA, insertions in genes, which render the genes unable to code for functional proteins; see Table 3 for an animation link). Other good topics for discussion include that Arabidopsis is a member of the mustard family (Brassicaceae) and is related to broccoli, cauliflower, and cabbage, as well as how information learned from studying Arabidopsis can be applied to agronomically important crops. The scientist may also provide information on the particular genes the students are studying.
This conversation leads to the next step in the research process: developing a research question and hypothesis.

\section{Phase 1B: Developing a Research Question \& Hypothesis}

Now that students have had an opportunity to think about what plants require for successful growth and development, they can begin thinking about how environmental conditions might influence a specific phenotype. PREP presents the following research problem: to understand the function of a gene, it is important to understand how removing the gene might influence the plant's phenotype. In particular, the impact of altering a gene may be apparent only in certain environmental conditions or when specific stresses are present, such as in high levels of salt created by heavy irrigation of soil. Many varieties of crop plants do not grow well in soil with high levels of salts. For example, one group of scientists identified Arabidopsis mutants that do not grow well in salt. These "salt overly sensitive" (SOS) mutants are useful for understanding how plants respond to salt in their environment (Zhu, 2000).

Teachers can help students develop investigable questions by highlighting three elements: (1) open-endedness, in that the gene could function in any process used by plants to respond to their environment; (2) underlying rationale (i.e., in what way is the independent variable relevant to plants and to the gene of interest?); and (3) alignment with an experimental strategy (i.e., the experiment can be set up and data collected in a way that can address the question, given the constraints of the classroom, including time, space, safety, and feasibility).

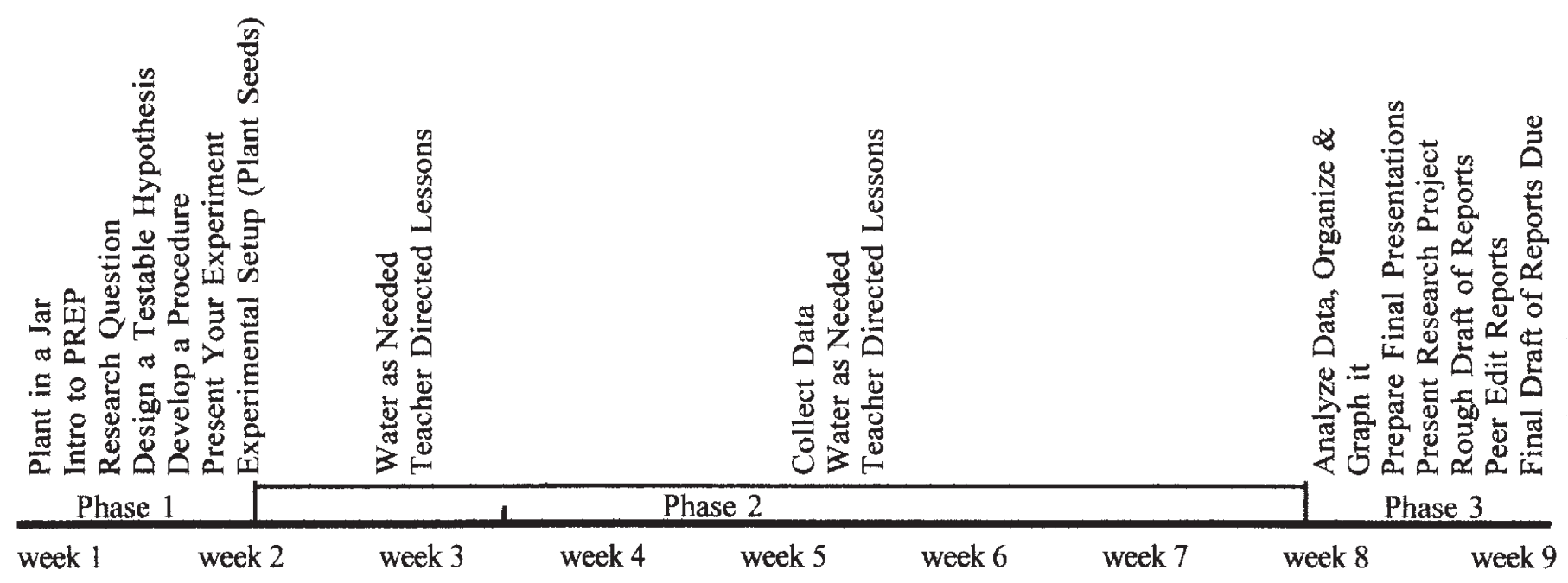

Possible timeline for conducting PREP. Can be modified for 45-90 minute class periods based on teacher's needs.

Figure 1. Timeline of PREP events. 
For example, students might propose that "Soils have varying amounts of salt in them and plants can grow differently depending on the salt content of the soil. Thus, our question is, 'How does watering with salt water affect the growth of wild-type versus mutant Arabidopsis plants?"' In this example, the students have justified their reasoning by explaining their thinking about how salt affects plants. This reasoning is then phrased in the form of a question that suggests that the variable in the experiment is salt water, and that plants might be affected by it. Some suggestions for experimental conditions can be found on the PREP website (Table 3), but students often enjoy the opportunity to be creative by coming up with their own conditions.

Once they have developed a research question, the students can write a hypothesis. The NRC (1996) recommends that students formulate a testable hypothesis that makes a logical connection to the experimental design. For example, using an "If... then..." statement to guide the formation of the hypothesis. Hypotheses developed using this structure can include three elements: (1) which condition(s) will be tested, (2) what results are expected, and (3) how those results will be measured. An example of such a hypothesis is, "If mutant and wild-type Arabidopsis plants are watered with salt water and the mutants cannot tolerate salt as well as the wild-type plants, then the wild types and mutants will show a difference in plant height and leaf size." This hypothesis indicates the conditions that will be tested (watered with salt water), the results that are expected (mutants will grow differently than wild types), and the differences that will be measured (plant height and leaf size). Of course, teachers have the freedom to use other approaches to guide students in constructing their hypotheses. In fact, some teachers do not guide their students in developing specific hypotheses at all, choosing instead to focus the students' attention on their research questions and on making decisions about what data to collect on the basis of observations they make at key points in the plants' development.

The next step is for the students to draft clear, step-by-step procedures. All the students will conduct some procedures, such as sowing and thinning the plants (see Table 3 for video links). Other steps, such as the application of treatments, will be specific to each group. One effective way of emphasizing the amount of detail that the students will need to include in their methods is to remind them of the general standard for publication in science: methods have to be detailed enough that anyone can understand them, so that the experiment can be repeated.

Controls for both the plant's genotype and the experimental treatment are inherent in the experimental design (e.g., four pots, one pot each of the wild type in control conditions, the mutant in control conditions, the wild type in experimental conditions, and the mutant in experimental conditions; Figure 2). Yet students generally need guidance to understand the rationale behind this design. This setup not only allows them to compare wild-type versus mutant plants to determine the impact of disabling the gene, it also allows them to compare experimental versus control plants to determine the impact of the treatment. Finally, by comparing wild-type and mutant plants in experimental conditions, the students can identify how disabling the gene influences the plants' response to the treatment.

Before starting their experiments, the students can improve their plans by sharing their research questions, hypotheses, and procedures with their classmates. This step allows for further refinement of their hypotheses and can give other students a chance to hear why students are researching a particular question. Class discussion at this point can be extremely rich, prompting "critical responses

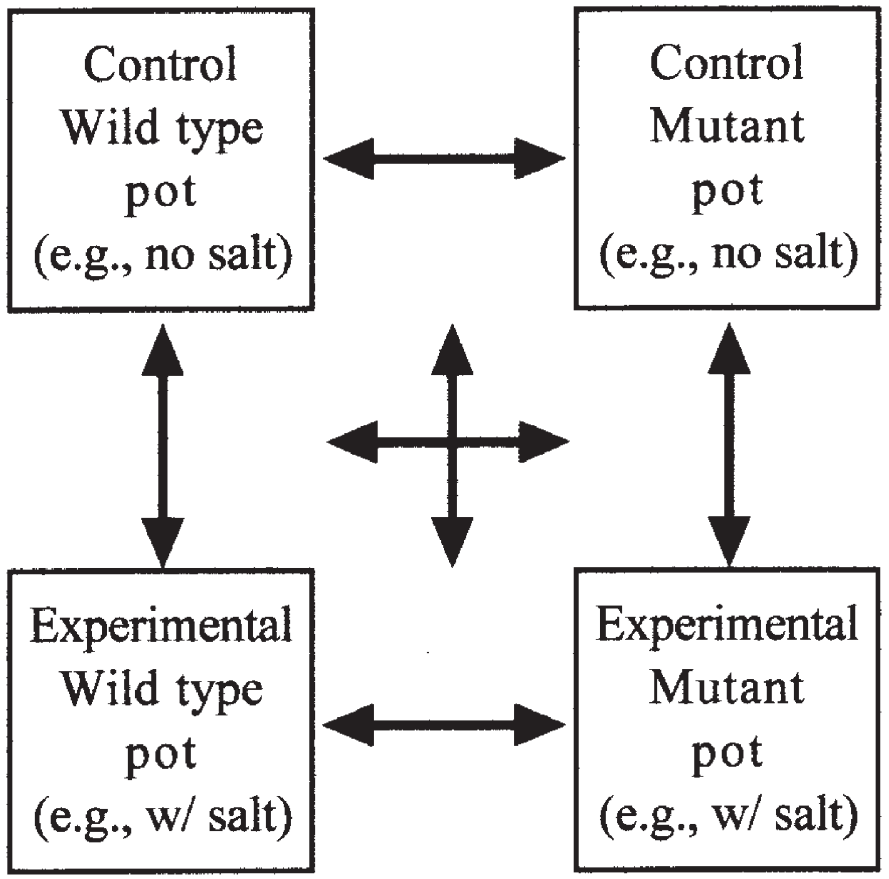

Figure 2. Experimental setup.

from peers" and spurring students to construct arguments to justify their designs (NRC, 1996). A sample rubric for evaluating and guiding students during these initial presentations can be found in the PREP Arabidopsis Timeline at http://www.prep.biotech. vt.edu/timeline/.

\section{Phase 2A: Growing \& Observing Plants}

Phase 2 begins with students planting their seeds. The PREP website has several brief instructional videos that offer a guided tour of the planting process (Table 3). One of the videos shows the procedure for stratifying (i.e., cold treating) the seeds prior to sowing so that they are more likely to germinate synchronously. Other videos demonstrate soil preparation and thinning so that about the same number of plants are growing in each pot, as crowding can affect plant growth and development. This is one place where teachers may choose to modify the project. Instead of growing Arabidopsis for the typical 6-week period, teachers may choose to pregrow the plants and then give them to their students for application of the treatment for only 3 to 4 weeks, which would cut the project time almost in half. Or teachers may have their students apply the treatment only during germination and early growth and development, again cutting the project time almost in half.

\section{Phase 2B: Collecting Data}

Once they have begun their experimental treatments, the students can turn their attention to collecting data. They can create their own datacollection tables and make their own decisions about which data are important to collect to test their hypotheses, or the teacher can direct them in their data-collecting efforts. For teachers who have not guided their students through data collection, the PREP website offers suggestions of biologically meaningful data to collect. Once again, the depth of the data-collection phase is up to the teacher. Students should be encouraged to record as much data as possible, since they cannot collect data once the plants have grown and reproduced, but they can opt not to analyze or draw conclusions about all the data they collect. 
Data collection can be expanded or limited on the basis of time available and may only take part of a class period, leaving the remaining time for lessons on related topics like genetics, plant biology, and nature of science. For example, the teacher can start PREP with activities and instruction on genetics to develop the students' understanding of the genetics behind the Arabidopsis mutants. Then, as the plants grow, the teacher can emphasize plant growth and development, so that the students can better understand their plants' responses to selected environmental variables. Although the quantitative aspects of data collection can be emphasized, the teacher can also emphasize the creative and imaginative elements of science while the students are engaged in PREP. For example, the students can be creative in the selection of growth conditions. In fact, many PREP scientists appreciate the creativity students bring to their brainstorming about environmental conditions and experimental design.

\section{Phase 3A: Analyzing \& Making Meaning of Data}

As the plants reach the end of their 6-week life cycle, the students can turn their attention to analyzing the data and making meaning of the results. First, they can represent their data in graphic and other visual forms to make differences among the four sets of plants more apparent. Second, they can calculate averages and conduct statistical analyses to determine whether differences are statistically significant. Finally, the scientist can examine the data and plants alongside the students. The scientist may recognize phenotypes and experimental issues that are not as apparent to less experienced researchers. Students in one teacher's advanced classes are asked to run either a chi-square or a t-test analysis on the primary data that they collect to determine the statistical significance of their findings and to learn about the role that mathematics plays in science (NRC, 1996). The instructional goal here is to help the students realize that data tell a story and that part of that story is figuring out if any differences are "big" enough to warrant further investigation. Sometimes the analyses reveal a significant difference in growth or development, and sometimes the plants grow similarly under various conditions, which suggests that the gene of interest does not help the plants respond to the selected treatments. These results will also be of interest to the scientist, but students may need reminding that negative results can be informative and can still contribute to the body of knowledge about Arabidopsis genes and their functions.

\section{Phase 3B: Communicating Results}

Although not all students share their findings in a formal way, some students prepare and present their work in oral presentations and written lab reports. The aim is for students to develop their communication and argumentation skills (NRC, 1996). Presentations offer another opportunity to invite the scientist back to the classroom to see firsthand the results of the students' projects. Some classes prepare science-fair-style posters to use as a visual aid as they discuss their projects with their classmates. In some classes, these presentations precede the preparation of lab reports so that the students can further develop their thinking about their experiments, especially the meaning of their results, before writing about them in depth (NRC, 1996). Posters also provide an opportunity to discuss the significance of their findings in a group setting. The rubric developed by one teacher to evaluate presentations and provide feedback to students can be found in the supplemental material on the PREP website.

Written lab reports can be either formal or informal. Again, teachers are free to determine the scope of work for the written reports. The timeline (Figure 1) suggests that students be given 1 day to write a rough draft of the report and 1 day for peer editing of the report before the final draft is due (see the supplemental material for peer editing questions used in one classroom). If writing is a major component of the curriculum, then expecting students to revise their draft several times before final submission may be more appropriate.

\section{O Grading \& Evaluation}

The complete PREP investigations span 5 to 9 weeks, which is much longer than students' typical laboratory learning experiences. It is useful to set a number of waypoints for feedback and evaluation to help the students organize their experiments and accomplish each task within the experiment. For instance, they might earn points for writing a well-developed hypothesis and a reasonable procedure. Students can also be required to collect data in some logical and coherent format, on which they are graded periodically during the data-collection phase. For some teachers, final presentations and reports provide the most significant evaluation opportunities. Again, teachers are free to determine their own grading system.

\section{Discussion}

Arabidopsis thaliana is a classroom-friendly organism because of its sturdiness, small size, and short life cycle, and because it has many available genetic and genomic resources. PREP provides a context for students to conduct authentic research on Arabidopsis and make discoveries that contribute to the body of scientific knowledge. High school students can be strong partners in research, providing novel ideas for experimental conditions and collecting data that can yield insights into the functions of Arabidopsis genes. For example, one Virginia class participating in PREP discovered that plants mutant for an enzyme that helps in the biosynthesis of compounds known as flavonols produced more plant pigments. This finding was acknowledged in a scientific publication (Owens et al., 2008). Furthermore, teachers, students, and scientists can all benefit from this collaboration by providing unique opportunities for each other and fulfilling some of the challenges that exist in their individual positions.

\section{$\bigcirc$ Acknowledgments}

Thanks to PREP students, teachers, and scientists. Initial support for PREP was provided by funding from the National Science Foundation (NSF; DBI-9975808). Continued development of PREP and preparation of this publication were made possible by funding from NSF MCB-0418946 and IOS-0922678, as well as from grant R25 RR08529 from the National Center for Research Resources (NCRR), a component of the National Institutes of Health (NIH). The contents of this paper are solely the responsibility of the authors and do not necessarily represent the official views of NCRR, NIH, or NSF.

\section{References}

Dolan, E.L., Lally, D.J., Brooks, E. \& Tax, F.E. (2008). PREPping students for authentic science. Science Teacher, 75, 38-43.

Lally, D.J., Brooks, E., Tax, F.E. \& Dolan, E.L. (2007). Sowing the seeds of dialogue: public engagement through plant science. Plant Cell, 19, 2311-2319.

National Research Council. (1996). National Science Education Standards. Washinģton, DC: National Academy Press. 
National Science Foundation. (2001). The 1999 report of the NSF-Sponsored Workshop: "New Directions in Plant Biological Research." Available online at http://www.arabidopsis.org/info/ carnegieworkshop.html.

Owens, D.K., Alerding, A.B., Crosby, K.C., Bandara, A.B., Westwood, J.H. \& Winkel, B.S.J. (2008). Functional analysis of a predicted flavonol synthase gene family in Arabidopsis. Plant Physiology, 147, 1046-1061.

Zhu, J.K. (2000). Genetic analysis of plant salt tolerance using Arabidopsis. Plant Physiology, 124, 941-948.
ERIC BROOKS is a biology teacher and Ph.D. candidate in molecular and cellular biology at the University of Arizona, Life Sciences South no. 210, PO Box 210106, Tucson, AZ 85721-0106; e-mail: ebrooks@email.arizona.edu. ERIN DOLAN is Associate Professor of Biochemistry at Virģinia Tech Fralin Life Science Institute, West Campus Drive MC 0346, Blacksburg, VA 24061; e-mail: edolan@vt.edu. FRANS TAX is Associate Professor of Molecular and Cellular Biology at the University of Arizona, Life Sciences South no. 346, PO Box 210106, Tucson, AZ 85721-0106; e-mail: fetax@u.arizona.edu.

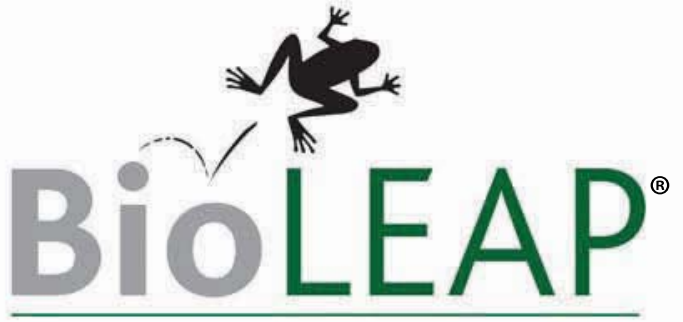

BIOLOGY EDUCATION ADVANCEMENT PROGRAM

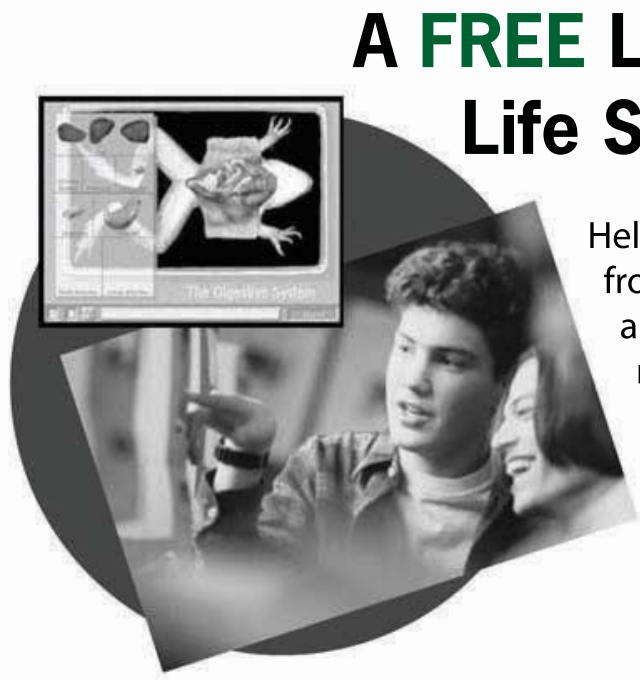

A FREE Lending Library of Science Teaching

Help your students jump ahead in the science lab! Choose from our state-of-the-art collection of CD-ROMs, models, software and videos. With more than 18 species available, BioLEAP® ${ }^{\oplus}$ has the most comprehensive selection of FREE dissection alternatives for your classroom.

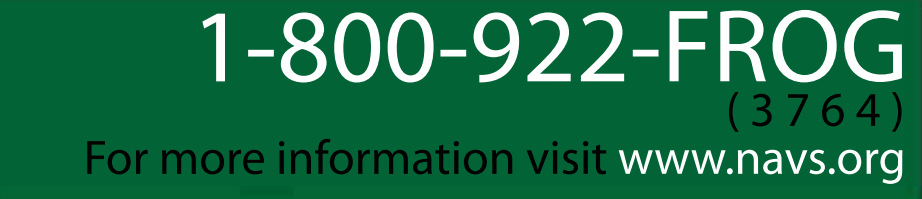

A program of The National Anti-Vivisection Society 53 W. Jackson Blvd., Suite 1552 Chicago, IL 60604 @2010 NAVS 